Perspectivas - Portuguese Journal of Political Science and International Relations, N. ${ }^{\circ} 11$, December 2013, 7-29 (c) NICPRI 2013

\title{
A Moralidade da Distância e da Guerra sem Risco
}

João Vicente

João Vicente

Centro de Investigação em Segurança e Defesa do Instituto de Estudos Superiores Militares

joao.vicente.6@gmail.com 
RESUMO:

A condução da Guerra de acordo com princípios éticos, não só é moralmente correta, mas revela a humanidade da sociedade moderna. Ao confrontarmos a introdução de uma nova tecnologia no espaço de batalha com os princípios éticos e legais universalmente aceites, estamos a garantir os padrões morais das futuras gerações. A possibilidade de conduzir uma Guerra virtuosa, porque cirúrgica, consciente e escrupulosa, contrasta com o argumento de que se trata de uma Guerra virtual em que as imagens de vídeo reduzem o conflito a um distante jogo de consola. Uma das maiores críticas apontadas aos sistemas aéreos não tripulados, quando comparados com a alternativa viável, a tripulada, é de que infligem danos desproporcionados e desnecessários nomeadamente em civis, em resultado do afastamento físico e da eventual desconexão emocional dos seus operadores

\section{Introdução}

A tecnologia define o que é possível, restando ao homem decidir o que é correto. Conscientes do impacto operacional dos Unmanned Aircraft Systems (UAS) ${ }^{1}$, na conflitualidade atual, é importante efetuar uma reflexão crítica sobre a moralidade do emprego destes sistemas na Guerra. Nesse sentido, pretendemos determinar neste ensaio as possíveis implicações éticas desta modalidade de combate. Ao estudarmos esta temática procuramos descortinar de que forma é que o afastamento físico dos operadores de UAS da zona de combate irá influenciar o seu comportamento. Confrontados com este dilema tentaremos indagar se esse fenómeno contribuirá para esbater os julgamentos morais e desumanizar o inimigo, ou tornar as decisões mais racionais porque não existe exposição física aos rigores da batalha.

Assumindo um emprego correto, os drones possibilitam uma maior capacidade de distinção entre objetos militares e civis. Em resultado de melhores capacidades de vigilância e de precisão, estes sistemas melhoram o conhecimento da realidade, criando sinergias que não estão disponíveis aos pilotos de aeronaves tripuladas. Tendo em consideração que os operadores não estão sujeitos ao risco físico e ao stress do combate tradicional, podem efetuar uma análise mais cuidada dos alvos. O somatório destas capacidades poderá contribuir para um emprego mais proporcional e uma maior discriminação.

Uma das maiores críticas apontadas aos UAS, quando comparados com a alternativa viável, a tripulada, é de que infligem danos desproporcionados e desnecessários, nomeadamente em civis, em resultado do afastamento físico e da eventual desconexão emocional dos seus operadores. O que está em causa é a dessensibilização do combatente e a perda da aversão à morte. Esta convergência de "execuções seletivas" com jogos de vídeo é uma experiência original para a civilização humana.

A condução da Guerra de acordo com princípios éticos, não só é moralmente correta, mas revela a humanidade da sociedade moderna. Ao confrontarmos a introdução de uma nova tecnologia no espaço de batalha com os princípios éticos e legais universalmente aceites, estamos a garantir os padrões morais das futuras gerações. A possibilidade de conduzir uma Guerra virtuosa, porque cirúrgica, consciente e escrupulosa, contrasta com o argumento de que se trata de uma Guerra virtual em que as imagens de vídeo reduzem o conflito a um mero jogo de consola. 
Numa perspetiva ética, a Guerra à distância tem desafios óbvios confirmados pela história da conflitualidade hostil. Contudo, o debate acerca da distância a que a imposição da morte se torna aceitável é estéril. Isto porque não interessa o local onde o piloto se encontra, mas sim a razão e a forma como a morte é imposta. Neste sentido, não existe diferença entre um bombardeiro tripulado que larga as suas bombas guiadas a uma altitude de $30.000 \mathrm{ft}$ e um drone que vigia uma área na procura de alvos de oportunidade. Importa por isso verificar se o aumento da distância poderá ser associado com abstração ou indiferença à morte. E numa era em que a Guerra Aérea Remota se ameaça transformar num instrumento de morte à escala industrial (Nagl, 2011), será importante debruçarmo-nos sobre os efeitos morais de tal emprego generalizado.

\section{O distanciamento físico e a desconexão emocional dos Guerreiros Virtuais}

O estabelecimento de uma relação causal entre o distanciamento do combatente do ato de matar corpo a corpo, e a probabilidade de aumentar a eclosão da Guerra é difícil de estabelecer. Todavia, caso essa relação exista, então ela será sublimada pelos UAS, obrigando a uma diluição da perceção tradicional de combate. A história do Poder Aéreo não é alheia aos debates incisivos sobre a legitimidade do seu emprego. Desde logo, pela ideia de que o bombardeamento aéreo pudesse constituir-se como tática desumana em virtude de semear indiscriminadamente a morte na sociedade. A questão central tem a ver com a alternativa disponível. Será ela mais humana? Provocará menos baixas civis? Com que risco para o combatente?

Desde o início da conflitualidade hostil que o homem procura aumentar a distância entre si e o adversário, procurando matar com maior precisão e menor risco. Faca, lança, besta, espingarda, canhão, blindado, avião, submarino, míssil de cruzeiro. A procura de invulnerabilidade relativa, se bem que temporal, é um desiderato do homem ao longo da história da Guerra. Os avanços tecnológicos que foram afastando o homem do campo de batalha também criaram discussões semelhantes acerca da justiça do combate. A imposição da morte à distância ou numa posição de impunidade tem sido recebida com resistência pelos praticantes tradicionais da Guerra. A proibição imposta pelo Papa Inocêncio II em 1139 ao uso da besta, considerada uma arma desumana, e o boicote atual ao emprego de armas inerentemente indiscriminadas como as biológicas, as minas, os laser antipessoais, ou as munições cluster (dispersão/fragmentação), são disso exemplos.
O estabelecimento de uma relação causal entre o distanciamento do combatente do ato de matar corpo a corpo e a probabilidade de aumentar a eclosão da Guerra é difícil de determinar. Todavia, caso essa relação exista, então ela será sublimada pelo emprego de drones de combate, obrigando a uma diluição da perceção tradicional de combate. Importa por isso verificar se o aumento da distância poderá ser associado com abstração ou indiferença à morte. E numa era em que a Guerra Aérea Remota se ameaça transformar num instrumento de morte à escala industrial, será importante debruçarmo-nos sobre os efeitos morais de tal emprego generalizado.

PALAVRAS-CHAVE: Guerra Aérea Remota, Unmanned Aircraft Systems, drones, moralidade 
Outros casos de inovações que aumentam a distância e o santuário dos combatentes, o franco-atirador (sniper) ou o submarino, produziram sentimentos semelhantes de hostilidade, injustiça e mesmo ódio, nos inimigos que não dispunham das mesmas capacidades (Trsek, 2008: 45-56).

Nem o brilhantismo de Leonardo da Vinci, ao equacionar precocemente o emprego de máquinas voadoras em combate, imaginaria a realidade atual da Guerra Aérea Remota. Uma realidade em que um piloto enfrenta os engarrafamentos diários de trânsito no percurso para o trabalho, entra num cubículo preenchido de computadores e monitores, "voa" uma aeronave de combate para disparar mísseis guiados contra um adversário a milhares de quilómetros de distância, e no fim do seu turno de oito horas vai buscar os filhos à escola e ainda tem tempo para ir fazer compras ao supermercado antes de confecionar o jantar em família (Martin; Sasser, 2010: 2).

Estamos perante uma nova era de "telecombate", onde o interface da Guerra Aérea é uma imagem em alta definição num monitor de computador, algures num bunker, a milhares de quilómetros de distância do impacto da bomba A desconexão física e emocional desta modalidade de operação remota, semelhante a um jogo de vídeo, altera a dinâmica da tomada de decisão, aumentando as preocupações sobre os princípios básicos de moralidade e humanidade que antecedem a decisão de matar um adversário. Este distanciamento "tele-epistemológico", que oferece uma perceção da realidade remota mediada pela tecnologia, induz no operador de drones uma consciência situacional diferenciada e faz questionar o impacto da distância na sua capacidade para tomar decisões éticas (Sullins, 2009).

O relatório submetido ao Conselho dos Direitos Humanos, sobre a problemática "execuções seletivas", refere que o aumento da distância pode provocar uma dessensibilização à morte similar à experiência vivida nos jogos de vídeo. Esta "mentalidade de combate Playstation", por parte de indivíduos que nunca foram expostos aos riscos e rigores da Guerra, pode originar excessos e desrespeitos das convenções internacionais (Alston, 2010: 25). O receio de que a Guerra se possa transformar num jogo de vídeo é demasiadamente simplista. Contudo, a visão de que um jogador é normalmente "um Deus pouco benevolente" transmite a tendência para ações mais arriscadas e violentas, características do mundo virtual. Por outro lado, a maior intimidade da Guerra remota pode tornar os operadores imunes à morte (Singer, 2009b: 42). Este argumento assenta no pressuposto que quando não temos de enfrentar fisicamente o adversário, se torna mais fácil matar. 
Ao analisar o que motiva os soldados a matar e os efeitos disso sobre eles, Grossman (1996) teoriza que existe algo no comportamento dos combatentes que torna a ideia de matar outro ser humano uma anátema. O caso dos bombardeamentos incendiários da $2^{\mathrm{a}}$ Guerra Mundial e os bombardeamentos nucleares sobre o Japão revelam possíveis ocasiões, em que o distanciamento dos combatentes poderá ter contribuído para impor sofrimento e destruição, que de outra forma não seriam capazes de infligir (Ibidem: 102). Ao associar ao distanciamento físico, também um distanciamento psicológico, aponta a relação entre a distância física com a vítima e o trauma resultante da sua morte (Ibidem: 97). Desta forma, a desconexão física dos eventos impõe um desconhecimento da natureza e da extensão do horror da Guerra.

Nesta perspetiva, existe efetivamente uma tendência histórica de diminuição da resistência a matar em combate, à medida que a distância entre combatentes aumenta. Ou seja, quanto mais longe estiver o adversário, mais fácil se torna mata-lo. Por exemplo, a resistência a impor a morte através do bombardeamento aéreo a $20.000 \mathrm{ft}$ ou através do uso de artilharia situada a $2 \mathrm{~km}$ de distância do alvo, é mínima (Grossman; Christensen, 2008: 203). A estas distâncias, a despersonalização do alvo facilita o emprego de armamento, tornando a Guerra altamente impessoal. A história do combate tem sido marcada por uma série de evoluções no desenvolvimento de armas, cada vez mais eficazes, como instrumentos para diminuir a resistência do combatente a matar (Ibidem: 197-200). Por um lado, o homem procura nas armas uma forma de ultrapassar as suas limitações físicas ao nível da força, distância, mobilidade e proteção. Por outro lado, as armas desempenham uma função crucial no sentido de ultrapassar a resistência psicológica a matar outro individuo da mesma espécie.

Para além disso, é curioso notar que a história do combate demonstra que a imposição da morte através do ar, em particular em combates entre aeronaves, é aceite com maior naturalidade pelo próprio combatente do que uma morte imposta por um soldado no terreno (Ibidem: 312). Esta diferença de sentimentos poderá ser atribuída ao modo como cada um dos combatentes processa a morte e à forma como este processo foi ritualizado ao longo da história. Enquanto o abate de uma aeronave adversária por um piloto de caça é celebrado pelo próprio piloto, glorificado pelos seus pares e o seu heroísmo louvado pelos seus superiores, garantindo um lugar na história, a morte causada por soldados no terreno raramente é celebrada pelo próprio, ou pelos seus superiores e pares.

Todavia, com o aumento da distância, o efeito psicológico sobre o inimigo é mais reduzido, na medida em que o combate a curta distância, e em particular o medo 
sentido por poder ser morto em combate próximo, é que modifica o comportamento do adversário (Ibidem: 204). Neste sentido, a visão pessoal da morte e destruição torna-se extremamente eficaz a modificar o comportamento humano. Por outro lado, as armas que constituem uma ameaça direta são psicologicamente mais eficazes do que as armas de área. Ou seja, o atirador furtivo é psicologicamente mais eficaz do que uma salva de metralhadora, ou uma bomba de precisão tem maior impacto psicológico do que uma barragem de fogo de artilharia (Ibidem: 204). De igual forma, a constante antecipação de ser atacado pode ter um efeito nefasto, em particular quando esta incerteza se prolonga no tempo (Ibidem: 273).

Podemos assim concluir que apesar do aumento da distância, quanto mais precisa é a arma, maior é o medo que inspira ao adversário. Se a isto adicionarmos um carácter de furtividade, surpresa e incerteza acerca da chegada da morte, conseguiremos levar a extremos o efeito psicológico sobre o inimigo. É nesta perspetiva que a quase omnipresença do bombardeamento de precisão revela o efeito psicológico devastador da Guerra Aérea Remota.

As convicções de Clausewitz $(1989: 75 ; 149)$ sobre o facto de a Guerra ser um confronto físico entre dois oponentes, com derramamento de sangue, torna-a diferente de qualquer outra forma de conflito ou competição. A Guerra é uma forma de conflitualidade, hostil, com custos humanos elevados que tornam o seu emprego politicamente e publicamente escrutináveis em sociedades democráticas ocidentais. Todavia, a citação em apreço parece ter perdido o seu dogmatismo com o advento da Guerra Aérea Remota. A eliminação do risco e do medo interrompe a ligação ancestral entre Guerra e perigo físico que define a essência do combatente, reduzindo o heroísmo e valor em combate a metáforas virtuais.

A condução de uma campanha aérea com UAS levantará preocupações acerca dos critérios de Guerra Justa. Assim, poderemos questionar se apenas será permissível matar na Guerra quando exista risco para o ofensor. Isto porque a assunção do risco físico, em última análise da própria vida, inerente à profissão militar, distingue a Guerra das outras atividades humanas.

\section{Alternância entre proximidade, afastamento e permanência}

A alternância entre proximidade (intimidade com os acontecimentos) e afastamento (distância física do espaço de batalha), a que se junta uma permanência temporal aumentada, torna mais complexa a análise dos efeitos da Guerra Aérea Remota. Isto é, as melhorias verificadas na capacidade de transmissão de vídeo em 
tempo real distorcem os efeitos da distância entre o operador e o alvo, afetando qualitativamente o risco de danos para os inocentes.

Derek Gregory (2011) advoga que apesar do processo de ataque incorporar mecanismos quase-judiciais, a proximidade emocional com as forças amigas aumenta $o$ risco para os não combatentes. Isto porque, a visão em alta definição do sofrimento das forças amigas propícia o emprego de força letal, e com ele a possibilidade de causar danos colaterais. Apesar de estarem a milhares de milhas de distância física do alvo, os operadores dispõem de visão em alta definição que lhes fornece uma sensação de proximidade com a ação, característica dos jogos de vídeo. Este efeito de proximidade resultante de estímulos multissensoriais (imagem e áudio) aumenta, por um lado, a consciência situacional dos operadores, mas por outro personaliza o combate tornando-o mais intimo, em particular quando forças amigas estão sob ataque (troops in contact). A visão quase microscópica dos alvos e da destruição em alta resolução parece contribuir para agravar este sintoma. A consola de vídeo mostra não só a destruição imposta mas também a sequência dos eventos, ao contrário da presença efémera do piloto na área do alvo. É que, apesar do reduzido campo de visão do monitor, a consciência situacional sobre o evento no terreno é provavelmente maior do que a perspetiva momentânea de um piloto, que bombardeia um alvo e abandona a área em escassos minutos. O operador observa, ouve, durante horas, de forma sistemática, ganhando uma maior compreensão temporal, e apesar de estar fisicamente mais longe assiste de forma mais prolongada e intensa aos eventos.

A visão de camaradas a serem mortos no terreno, sem que o operador possa fazer nada por eles traduz uma sensação de impotência com marcas psicológicas profundas. Nesse sentido, a proximidade dos eventos que se desenrolam no terreno induz uma personalização do combate, que reforça os efeitos resultantes da dessensibilização provocada pela deslocalização geográfica da ação. Assim, a dicotomia concetual da distância, que simultaneamente separa fisicamente os operadores de UAS, mas imerge-os psicologicamente em combate, poderá contribuir de forma sinérgica para precipitar o uso de força letal contra elementos na proximidade das forças amigas, aumentando as possibilidades de danos colaterais e fratricídio.

Outro dos fatores que importa realçar no que concerne à dessensibilização à morte por parte dos operadores, diz respeito à desumanização do inimigo. Ao longo da história da conflitualidade hostil, o homem sempre procurou diminuir o impacto psicológico da morte para aqueles que a infligiam em nome do Estado e do interesse nacional. O processo de desumanização do inimigo é uma cons- 
tante da Guerra no sentido de diminuir as barreiras ao combate, quer da parte da sociedade, quer do próprio militar que impõe a morte ao adversário. ${ }^{2}$ Ao remover as qualidades humanas do adversário, como por exemplo a demonização do oponente ${ }^{3}$, facilita-se o seu combate, tornando a violência mais aceitável. Esta desconexão moral predispõe a execução de atos violentos que doutra forma não seriam considerados nem aceitáveis (Bandura, 2004: 135-137).

É seguindo este raciocínio que autores como Wilson (2011) advogam que o afastamento psicológico resultante da condução da Guerra Aérea Remota implica uma nova forma de desumanização do adversário. Para ele, ao manterem a distância da agonia humana, transformam a Guerra real numa simulação brutal, facilitando o desprendimento moral das ações letais. Com o aumento da autonomia dos UAS e antecipando a transição da função humana de executante para supervisor, é possível antecipar um agravamento desta condição (Royakkers; Est, 2010: 292).

Neste sentido, é possível encontrar alguns indicadores que confirmam a desumanização da Guerra Aérea Remota. Um desses indicadores diz respeito à nomenclatura empregue nas operações. Por exemplo, a referência aos insurgentes mortos no Paquistão por mísseis disparados de drones como "bugsplat"4 acentua a técnica psicológica de desumanização dos alvos, diminuindo a inibição para matar e tornando a morte mais aceitável. Também os próprios nomes dos sistemas de armas não tripulados reforçam este carácter desumano e impiedoso (Sifton, 2012). Os drones americanos de combate mais utilizados na última década são o Predator e o Reaper. O nome Predator sugere uma destituição da humanidade do inimigo, transformando-o numa mera presa, e o combate numa caçada. $O$ sistema Reaper acrescenta a imagem do instrumento que ceifa os inimigos destinados a morrer, e o míssil Hellfire invoca o sentido de justiça e de punição numa outra vida. Se a isto juntarmos o facto de os drones serem empregues para impor a morte seletiva a pessoas em vez de forças ou infraestruturas militares, verificamos estar perante uma dicotomia de intimidade, em que por um lado, a forma mais íntima de violência - a "execução seletiva" de um indivíduo - contrasta com o afastamento entre os combatentes.

Este ambiente de combate sintético propicia a desumanização dos inimigos e como tal, a desconexão moral dos operadores, que se reflete na dessensibilização à morte e com ela uma maior probabilidade de ocorrência de comportamentos antiéticos. Numa perspetiva tecnológica, a imersão neste ambiente de realidade virtual, faz esbater as diferenças entre um jogo de vídeo e a realidade, confundindo 
um alvo virtual e um alvo real, ao mesmo tempo que no plano ético provoca um distanciamento físico e emocional das ações produzidas. Neste cenário extremo, também o operador será desumanizado, privado de sentimento moral de responsabilidade, ou de culpa pelos seus atos (Royakkers; Est, 2010: 293).

Até certo ponto, a Guerra nunca poderá ser moral, mas é nossa obrigação tentar moralizá-la mais. E nesta perspetiva, existem vários mecanismos que podem servir para humanizar a condução da Guerra Aérea Remota. As regras de operação de UAS tentam emular as rotinas características de uma missão tripulada. A United States Air Force (USAF) faz tudo o que pode para assegurar que os operadores de UAS se comportam da mesma forma que os pilotos de aeronaves tripuladas. Desde o fardamento até ao briefing de missão, tenta-se replicar o "ethos" do combatente (Bushey, 2011). A condução de uma tarefa virtualmente isenta de risco, requer por isso uma disciplina assinalável por parte dos operadores, nomeadamente adesão a regras de empenhamento, assim como acrescenta desafios de supervisão. Para minimizar os efeitos estratégicos de possíveis danos colaterais, a liderança política e militar impõe constrangimentos e restrições ao uso de armas, táticas e protocolos de seleção de alvos.

Ao longo da história da Guerra, à medida que a distância de combate aumenta também crescem os riscos de causar baixas amigas resultantes de erros de identificação positiva (Regan, 1995). O advento da Guerra Aérea veio adicionar uma nova dimensão ao problema do fratricídio (Rasmussen, 2007). Apesar dos números totais de baixas amigas terem decrescido substancialmente, os erros ao nível tático originam efeitos adversos ao nível estratégico, com uma rapidez cada vez maior. Isto porque nas últimas décadas, a tolerância às baixas em combate, amigas ou civis, tem vindo a reduzir-se à medida que o modo americano de fazer a Guerra se torna cada vez mais dependente da tecnologia, fazendo aumentar as expetativas de precisão cirúrgica a que a sociedade ocidental tem vindo a ser habituada pelos militares e pelos media.

Neste sentido, a operação de UAS oferece uma vantagem tática. Ao remover o risco físico e com ele o medo associado ao combate permite diminuir a pressão dos seus operadores. Um ambiente de "combate" mais confortável, com recurso a mais informações e com disponibilidade de múltiplos sensores, contribuem para decisões mais sustentadas. Todavia, isto não significa que estas sejam isentas de erros. Apesar da tecnologia permitir ver e ouvir tudo o que se passa no espaço de batalha, não significa que não subsistam os problemas de distinção entre amigo e adversário. Para além disso, embora a sobrevivência do operador de UAS não 
esteja dependente dos riscos tradicionais da aviação tripulada, não significa que as consequências dos seus erros de julgamento não possam ser igualmente letais.

Um exemplo desta observação ocorreu a 21 de fevereiro de 2010 quando um helicóptero americano disparou mísseis Hellfire contra uma coluna de três veículos afegãos. O relatório preliminar da investigação ao incidente concluiu que procedimentos incorretos e não profissionais de operadores de UAS, que estavam a seguir a coluna de veículos a partir da sua estação de controlo no Nevada, contribuíram para o ataque aéreo que matou 23 afegãos, incluindo uma mulher e três crianças, deixando outros 12 feridos. Apesar da capacidade de discriminação fornecida pelos UAS, os erros de análise dos operadores implicaram a transmissão de informação incorreta às forças amigas de que os veículos apenas transportariam homens armados (Brulliard, 2010). Numa versão completa do referido relatório, recentemente desclassificada, é destacada a propensão dos operadores para ações cinéticas como fator causal deste incidente. ${ }^{5} \mathrm{O}$ registo imaculado dos UAS foi também manchado em abril de $2011 \mathrm{com}$ o primeiro caso reportado de fratricídio, em que dois militares americanos foram mortos por um míssil disparado de um Predator, em resultado da combinação fatal de comunicações incorretas, pressupostos errados e uma falta de consciência situacional comum (Zucchino; Cloud, 2011).

Independentemente das razões evocadas, o estudo sobre o fratricídio ao longo dos dois últimos milénios aponta para que se mantenha uma constante histórica: em última análise, é o homem que comete erros. Pelo stress, medo de morte, de humilhação e de falhanço. Os erros começarão a reduzir-se a partir do momento em que estes sentimentos desapareçam da equação. Mas nessa altura, talvez deixaremos de estar perante a Guerra, ou então ela não será combatida por homens (Regan, 1995: 240).

\section{O virtuosismo da Guerra virtual}

Esta é outra das novidades introduzidas na Guerra. A exposição alternada a uma realidade semi-virtual poderá fazer emergir o pior de três mundos: o stress das missões, a dessensibilização dos jogos de vídeo e o impacto psicológico da transição entre ambientes físicos e sintéticos (Saletan, 2008).

As implicações do relacionamento do indivíduo com a Guerra fazem-se notar na própria experiência da Guerra. "Ir para a Guerra" tornou-se um processo devidamente ritualizado em que se pressupunha a assunção do risco da própria vida. 
Implicava a separação dos entes queridos e a exposição aos horrores do combate. Isto mudou irremediavelmente com a operação remota de UAS, tornando cada vez mais difícil distinguir o evento "ir para Guerra" de "ir para o trabalho" (Singer, 2009a: 327). A habilidade da geração "Playstation" torna-a indicada para gerir as múltiplas tarefas com a rapidez exigida pelos conflitos atuais, porém, esta habituação à realidade virtual faz distorcer a realidade da Guerra (Singer, 2010a). No ambiente asséptico da consola do operador do Reaper, as explosões parecem autênticos jogos de computador, onde a diferença de um jogador para o operador reside nas consequências reais dos clicks no rato. Comparativamente com a vivência operacional do combatente terrestre, o horror da Guerra não é tão nítido quando visto de um monitor. Contudo, apesar do afastamento entre combatentes poder facilitar a imposição da morte, não os isenta de sentir remorsos. Apesar da agilidade natural da geração "Playstation" em alternar entre os dois mundos, esta nova geração não compreende o horror da Guerra, nem os laços de camaradagem e de espírito de corpo que se fortalecem em combate e que não são reproduzíveis em ambientes sintéticos. A coesão entre a unidade de combate tende, por isso, a desaparecer.

Neste âmbito, o uso de UAS armados desafia as noções tradicionais do ethos militar e o estatuto moral da Guerra enquanto forma de violência. É esta possibilidade de competição letal, em que um combatente usa a força contra outro arriscando a própria sobrevivência, que distingue a essência da Guerra. Não será de esperar que esta nova geração de militares, apelidada por Dunlap (1999: 30) como "Guerreiros de Consola", e que faz a Guerra sem nunca ter sido exposta às suas consequências mortais, partilhe dos valores militares tradicionais que restringem a sua conduta ilegal e imoral.

O património imaterial dos militares, os seus valores e virtudes, consubstanciadas sob a forma do ethos militar, encontram as suas origens em conceitos de honra, bravura e cavalheirismo derivados da realidade física do combate direto. Ao pouparem os combatentes ao perigo e ao sacrifício, os UAS transformam a conflitualidade hostil numa modalidade de "Guerra sem Virtudes" isenta de coragem e de heroísmo. O "Guerreiro Virtual", poupado às condições austeras do ambiente de combate, é privado da identidade e do sentimento de pertença característicos do corpo de militares que tradicionalmente se submete ao risco de combate. Isto porque o ambiente operacional em que estão imersos não fornece a coesão e o relacionamento militar característico de um destacamento militar em zona de combate. 
O custo da formação e treino dos operadores é substancialmente mais reduzido do que o dos pilotos de aeronaves tripuladas. O rigor do treino físico e das técnicas de combate será bastante inferior ao necessário para um piloto de uma aeronave tripulada. Nesse sentido, as competências necessárias para os futuros "Guerreiros Virtuais" diferem em larga escala do processo de seleção atual. Historicamente ser "Veterano de Guerra" implicava ver, sentir e sofrer em exposição direta ao adversário. A assunção de risco físico, e da própria vida, conferia o estatuto heroico aos combatentes, refletido na atribuição de condecorações por feitos em combate. Apesar da USAF reconhecer que as tripulações de Predator e Reaper voaram grande parte das missões de combate nos conflitos da última década, estas não receberam o reconhecimento equivalente (condecorações) aos pilotos das aeronaves tripuladas. Por exemplo, numa operação em 2006 no Iraque, as tripulações de Predator efetuaram mais de 630 horas de voo na procura, localização e vigilância de Abu Musab al-Zarqawi. Após a sua identificação numa quinta a norte de Bagdad, um F-16 largou uma bomba de $500 \mathrm{lb}$ que matou Zarqawi. Ao piloto foi atribuída a Distinguished Flying Cross enquanto os operadores do Predator receberam uma nota de agradecimento de um general (Jaffe, 2010). Esta discriminação confirma a distinção institucional entre o combate real e virtual.

É por isso necessário replicar o enquadramento do ethos militar sob pena de se diluírem os padrões morais e éticos das instituições militares. A criação de uma "nova ética" de combate à distância está envolta em incerteza, mas a realidade demonstra o imperativo de instilar nesses combatentes, as fundações morais essenciais para a aplicação das normas éticas e legais nos conflitos futuros (Dunlap, 1999: 30).

A natureza remota do combate pode violar os valores históricos dos cavaleiros, de lealdade e bravura, presentes no combate próximo. Porém, o Direito da Guerra não obriga ao risco de exposição mútua dos adversários. Assim, a procura de maior eficácia e eficiência na Guerra constituem imperativos morais para os Estados democráticos, mandatados para garantir a segurança dos seus cidadãos.

\section{Stress de combate remoto}

Os estados elevados de vigilância (visual e auditiva) alternados com períodos de monotonia induzem desgaste acrescido à operação de UAS. Os longos períodos de operação por turnos, acumulando 50 a 60 horas semanais acrescentam maior esgotamento emocional às tripulações. A USAF não reconheceu o potencial para 
stress de combate quando iniciou esta tipologia de missões, assumindo que este tipo de stress só seria experimentado por pilotos de combate. Contudo, estudos recentes demonstram que a operação ininterrupta de UAS ao longo de uma década está a causar fenómenos de exaustão emocional e desgaste ocupacional, com consequências físicas e psicológicas que podem ser fatores contribuintes para um aumento de erros humanos em combate.

A existência de stress de Guerra nos operadores de UAS parece difícil de imaginar para aqueles que equacionam este tipo de operação como semelhante a um jogo de consola. Estudos sobre este fenómeno demonstram o impacto que a operação de UAS tem ao nível de problemas crónicos de fadiga (Tvaryanas et al., 2008). Isto porque, fruto da sua característica de persistência, a Guerra dos drones desenrola-se ao longo das 24 horas de forma ininterrupta. O aumento do ritmo operacional, com turnos de oito horas durante cinco a seis dias por semana, parece provocar um acréscimo dos níveis de fadiga, exaustão emocional e stress psicológico (Associated Press, 2008). Apesar do risco pessoal ter sido removido da operação dos UAS, o ritmo de operações, onde a natureza monótona das tarefas é interrompida por momentos intensos e imprevisíveis de combate, induz efeitos indesejados. Esta alternância de tensão provoca fadiga física e mental. Apesar disso, os operadores têm de responder de forma eficiente a vários estímulos visuais e auditivos, interpretá-los de acordo com os procedimentos estabelecidos sem degradar o seu desempenho (Chapelle et al., 2010: 4). Quando isso não acontece, os efeitos trágicos tornam-se tão reais quanto aqueles causados pelas aeronaves tripuladas.

A tecnologia tem um conjunto de pressões associadas. Tudo o que o operador ouve, vê e faz, fica gravado e é alvo de avaliações posteriores. A análise de uma missão é mais detalhada do que seria possível numa aeronave tripulada, fazendo aumentar a pressão dos operadores em justificar todas as decisões que tomam. Os efeitos da exposição prolongada à morte e destruição através de um monitor ainda não são bem conhecidos, mas estudos recentes mostram alguns dos indicadores mais relevantes das causas de stress. A natureza remota da operação de UAS protege os operadores das ameaças tradicionais à sua segurança pessoal, assim como minimiza os períodos de separação das suas famílias. Contudo, é possível identificar fatores de stress ocupacional nas vertentes operacional, de combate e de carreira, com impacto indesejável na operação de UAS (Chapelle et al., 2011: 19-2;19-3).

Os fatores mais comuns associados com o stress operacional, por ordem de preocupação dos operadores são: horário longo (mais de 50 horas semanais) e pessoal 
reduzido; trabalho por turnos com mudanças constantes dos horários; dificuldades de interface homem-máquina, nomeadamente a ergonomia do equipamento e da estação de controlo, assim como ineficiências nos procedimentos informáticos de controlo; localização geográfica indesejável; dificuldade em conciliar a vida familiar com as operações militares.

Os fatores de stress relacionados com o combate englobam entre outros, os ataques de precisão em que os erros têm um custo mais elevado (por exemplo o fratricídio ou a morte de civis); exposição a longas horas de imagens em tempo real de destruição e sofrimento; efetuar decisões críticas relativamente à identificação de inimigos e à proteção de forças amigas; ou o desafio único de conciliar a função de combatente com as responsabilidades familiares.

Os fatores relacionados com a carreira têm a ver com a falta de operadores resultante do número crescente de patrulhas de combate nos teatros de operações e da incapacidade dos programas de formação em satisfazer as necessidades operacionais. Como resultado disso, as comissões de serviço de três a quatro anos prolongaram-se no tempo e impediram o regresso dos operadores às aeronaves tripuladas de combate de onde foram recrutados. Por outro lado, dado que esta especialidade é relativamente recente apresenta uma progressão incerta, aumentando a desmotivação dos militares.

Estes resultados indicam que existe um alto nível de exaustão emocional entre os operadores de UAS em comparação com outros elementos militares não combatentes. ${ }^{6}$ Para além disso, a operação em turnos durante missões de vigilância provoca maiores índices de fadiga em operadores de Predator do que em tripulantes de aeronaves que efetuam o mesmo tipo de missão, podendo ajudar a explicar algumas das causas de acidentes devido a fatores humanos (Ibidem: 19-2). De igual forma, em resultado da combinação dos vários fatores de stress verifica-se um efeito psicológico negativo que poderá conduzir a um rápido desgaste ocupacional, em particular dos operadores de UAS que efetuam largada de armamento, com implicações nefastas na segurança de operação ou no sucesso da missão (Ibidem: 19-3). Apesar disso, os responsáveis da USAF não estabelecem uma ligação direta entre o stress acumulado e os erros humanos que causaram inúmeras situações de acidentes com UAS (Zoroya, 2011). Em contraste com os níveis de exaustão exibidos, os estudos efetuados revelaram uma baixa percentagem de stress pós-traumático. 


\section{Relação da sociedade com a Guerra}

O recurso extensivo aos drones parece indiciar uma desconexão da sociedade relativamente ao instrumento mais gravoso que está disponível a uma democracia: a Guerra. Esta possibilidade poderá advir de dois fatores: literal, em que não existem homens a combater, e contextual, que reflete a maior propensão para a conflitualidade hostil, em parte como resultado da desconexão da sociedade ocidental, em particular da americana, para com a Guerra Aérea Remota. Não podemos deixar de equacionar se a Guerra se torna cada vez mais virtual, sem sangue derramado, será que a sociedade se preocupará o suficiente para pedir maior moderação e exercer o controlo da força que é aplicada em seu nome?

A dependência ocidental do uso de UAS pode influenciar a perceção sobre a Guerra. Em particular a ligação da sociedade à Guerra. Numa sociedade em que o recrutamento militar obrigatório foi eliminado, onde as declarações de Guerra deixaram de existir, em que os orçamentos de defesa deixaram de ser prioritários, a remoção dos combatentes humanos do espaço de batalha afigura-se como a eliminação do derradeiro custo político e social de fazer a Guerra.

Aquilo a que Edward Luttwak (1995) apelidou de guerra pós-heroica assume atualmente novas proporções. O mesmo autor relembra que apesar das forças armadas modernas estarem estruturadas para a Guerra de larga escala, a base demográfica das sociedades avançadas pós-industriais, com famílias pequenas, demonstra uma tolerância reduzida para baixas em combate (Luttwak, 2007). Todavia, como destacámos anteriormente, a aceitação das baixas em combate depende dos interesses em jogo, da perceção da importância da Guerra e mesmo da capacidade dos líderes políticos em justificar a necessidade do conflito. Contudo, estas condicionantes podem tornar-se demasiado constrangedoras para uma grande potência, uma vez que a sua condição a obriga a arriscar combater para além dos seus interesses vitais, defendendo aliados, clientes ou outros fins periféricos (Luttwak, 2000: 136). É segundo este paradigma que a Guerra Aérea Remota revela a sua utilidade.

Como destacámos anteriormente, a Guerra Aérea Remota torna cada vez mais distantes o que Luttwak (2000: 132) denominou como as realidades eternas do combate - sacrifício mortal, bravura, medo e coesão, moral e liderança. Até mesmo o facto elementar de que a Guerra é acerca de matar e de ser morto sofreu uma alteração unilateral irremediável. Verificando a evolução histórica podemos constatar que a Guerra se tem tornado cada vez mais remota para a sociedade 
americana. Desde que se tornou uma atividade profissional, a Guerra foi privatizada, com recurso a outsourcing e a mercenários, tornando-se, figurativa e literalmente, em Guerra remota (Engelhardt, 2012). Confrontados com o dilema da necessidade do uso da força e do imperativo de redução de baixas, é possível justificar a proliferação atual de Empresas Militares Privadas e o recurso massivo aos UAS.

Para Mary Dudziak (2009), os drones contribuem para isolar cada vez mais a sociedade americana das ações militares, reduzindo o controlo da conduta política e ajudando a prolongar um período de Guerra perpétua. A indiferença da opinião pública ocidental à expansão global dos bombardeamentos aéreos por UAS é um dos indicadores de que os custos políticos de uma Guerra, em sociedades democráticas, são cada vez mais reduzidos. A questão dos drones ainda não mobiliza de forma significativa a opinião pública americana ao ponto do governo se sentir constrangido pelo seu emprego. Esta apatia está, por exemplo, refletida no debate insuficiente acerca das questões legais resultantes do emprego de drones pela Central Intelligence Agency no Paquistão.

Por outro lado, a indiferença que os UAS provocam na sociedade, transformando o cidadão-soldado em espetador, e a Guerra em mais um espetáculo televisivo que concorre por share com outras atividades lúdicas, levam a pensar que o escrutínio público desta atividade vital possa ter diminuído, e com ele fazer aumentar a frequência da Guerra. A realidade dos novos conflitos mostra também que o relacionamento do público com a Guerra é alterado, com a transformação das imagens de combate numa forma de entretimento, facilmente disponíveis e apelidadas de "pornografia da Guerra", onde podemos ver mais, mas experimentar menos (Singer, 2010b). O vídeo em tempo real da zona de operações e a sua disseminação pública ocorre de forma mais rápida e global do que em conflitos anteriores. Uma busca rápida no Youtube permite visionar centenas de vídeos em combate, onde a experiência da Guerra é mostrada de forma mais crua, não editada e acessível a qualquer cidadão, tornando-a mais familiar e menos repugnante, assemelhando-se a um jogo de vídeo. Algo que deveria causar medo e angústia, é visto agora como uma forma de entretenimento que recebemos no email diário. A vulgarização da experiência da Guerra, dos seus custos e das suas consequências pode em última análise levar a um completo desinteresse da sociedade.

Esta é apenas uma das facetas de um fenómeno mais extenso, apresentado por Peter Singer (2010a) como uma mescla de "militenimento"7 que molda a perceção da sociedade acerca dos conflitos contemporâneos. Para além de permitir 
treinar os seus soldados, também permite ao público um contacto mais direto com as operações reais, alterando as suas perceções da Guerra. Quando um avatar é morto basta apenas reiniciar o jogo, sem qualquer custo associado. Nesta modalidade, enviar um filho para a Guerra (virtual) não implica qualquer tipo de sofrimento.

As Forças Armadas existem porque pessoas estão dispostas a morrer pela sua pátria. Mas a Guerra Remota permite que os conflitos sejam travados sem dispêndio da própria vida. Este paradigma coloca-nos perante o risco de transformação do conceito histórico de Forças Armadas. Em última análise, Engelhardt (2012) alerta sobre o perigo da robotização militar como estágio final do outsourcing da Guerra para "coisas" que não protestam, não votam e para as quais não existe significado de mobilização nacional para combate. Todavia, podemos encarar o uso da tecnologia como uma forma de reduzir os custos e as paixões na Guerra, e como tal os seus crimes (Singer, 2009a: 393). A esperança de que novas invenções possam limitar a crueldade e os crimes da Guerra, evitando o derramamento de sangue é uma constante histórica da conflitualidade hostil. O mesmo se passa com os UAS. A omnipresença das câmaras no espaço de batalha modifica o contexto em que as decisões e também os abusos na Guerra são feitos. O impacto do Wikileaks ou do Youtube na revelação de crimes de Guerra, como no caso de Abu Ghraib, mostra que numa era da informação em que tudo é gravado, mesmo que não seja mais difícil cometer um crime, torna-se, pelo menos em teoria, mais fácil descobrir os criminosos e responsabilizá-los.

Com a retração dos teatros de operações contemporâneos será natural que se verifique um superavit de UAS que será direcionado para funções de segurança interna. Porém, esta atividade começa a levantar preocupações acerca do direito fundamental à privacidade individual, à medida que novas utilizações para drones militares em apoio de organizações policiais começam a ser testadas.

A extensão do problema é verificada pela informação oficial de que drones são operados atualmente nos Estados Unidos a partir de 63 locais em 20 estados, por entidades como a USAF, departamentos de segurança interna, agências policiais e mesmo Universidades (Gavaghan, 2012). Em 2011 a agência federal responsável pela aviação civil atribuiu 313 certificados para operação de UAS, estando prevista uma maior agilização no processo burocrático. A tal não é alheia a recente aprovação de legislação no Congresso para que esta agência federal desenvolva regulamentos que permitam, até 2015, o teste e licenciamento de drones comerciais (US Congress Report, 2012). Em resultado do enquadramento regulatório 
que favorece a integração em espaço aéreo geral, a própria agência federal de aviação prevê que nos Estados Unidos, nos próximos cinco anos, estejam ativos 10.000 UAS comerciais (FAA, 2012: 57).

Este desafio é tanto mais evidente, na medida em que a par com as capacidades de vigilância aérea do Department of Homeland Security e de algumas polícias estaduais, junta-se agora a oportunidade da poderosa frota de drones da USAF efetuar vigilância doméstica. A possibilidade da recolha de imagens de cidadãos americanos em território nacional, sem a sua autorização, está reconhecida em doutrina oficial (AFI 14-104, 2012: 11). Apesar de referida como uma possibilidade "acidental", estas imagens poderão ser analisadas para verificar possíveis ilicitudes e guardadas durante 90 dias antes de serem destruídas. Na prática, um voo que tem como objetivo monitorizar um parque nacional para detetar incêndios, poderá terminar com a abertura de um processo legal a uns campistas. Ou de forma mais intrusiva, registar indevidamente atividades ilícitas em qualquer propriedade privada.

A tendência histórica de introdução de um artefacto tecnológico numa tipologia de missão, que mais tarde resvala para usos indesejados, é o principal fator de preocupação no uso destes sistemas por entidades policiais em missões de segurança interna (Paumgarten, 2012). Da perspetiva legal, não existe diferença entre as imagens recolhidas por um drone ou por um helicóptero da polícia. Todavia, os drones fornecem uma persistência a custos inalcançáveis pelos sistemas tripulados, aumentando os incentivos para a sua utilização. Por sua vez, a generalização do seu emprego poderá favorecer o uso inadequado das imagens recolhidas. Mesmo em cidades onde a televigilância está disseminada, como por exemplo Londres, esta é apenas efetuada em espaços públicos. Em contrapartida, o carácter tridimensional acrescentado pelo vetor aéreo, associado às capacidades de exploração do espetro eletromagnético, amplificam este conceito para áreas tradicionalmente do foro privado.

Caminhamos a passos largos para uma completa omnisciência do espaço de batalha, que permitirá, segundo os seus defensores, monitorizar o quotidiano de um individuo numa sociedade, distinguindo onde vive, com quem se relaciona e o que faz, oferecendo opções mais variadas, letais ou não, de influenciar o seu comportamento. À medida que estes sistemas atingem níveis mais elevados de maturação, é possível antecipar a sua miniaturização e migração para outros domínios da interação humana, sob o auspício da segurança interna dos Estados. De uma perspetiva mais crítica e catastrofista, podemos encarar esta ambição de 
vigilância persistente e ubíqua como uma possível semente que faça germinar uma verdadeira sociedade orwelliana.

\section{Conclusão}

Ao nos debruçarmos sobre a moralidade da distância e da Guerra sem risco verificámos a possibilidade de desumanização dos combatentes, da sociedade e da Guerra. A alternância entre a intimidade com os acontecimentos, o afastamento físico do espaço de batalha e uma permanência temporal aumentada, induz maior complexidade na análise dos efeitos da Guerra Aérea Remota no próprio individuo. Esta dissonância cognitiva, nunca anteriormente presente de forma simultânea, afeta de forma paradoxal o paradigma da Guerra Aérea Remota, contribuindo para uma possível redução das barreiras ao uso da força letal, facilitando a decisão de matar e como consequência, aumentando o risco para os não combatentes, danos colaterais e fratricídio. Contudo, a tese de que o afastamento do campo de batalha contribui para a desumanização do alvo, deixando os soldados indiferentes à morte, contrasta com o argumento de que pelo facto dos operadores não estarem expostos ao risco e stress de combate, estes podem tomar decisões eticamente mais corretas do que aquelas tomadas por soldados no terreno. Para além disso, os operadores de drones estão sujeitos a uma maior supervisão uma vez que desempenham as suas funções num ambiente em rede em que todas as ações são gravadas, passíveis de escrutínio detalhado e de responsabilização individual.

O maior afastamento entre combatentes pode induzir uma despersonalização do combate, resultante de menor empatia com as vítimas, que facilita a imposição da morte. Para além de infligir a morte à distância, tal como os bombardeamentos aéreos por aeronaves tripuladas, a Guerra Aérea Remota traz consigo uma maior intimidade e identificação com as forças amigas no terreno, traduzidas numa proximidade sensorial resultante da vigilância persistente em alta resolução. Em comparação, os meios tripulados não expõem o piloto ao mesmo grau de imersão sensorial no ambiente de batalha, nem em espaços temporais tão prolongados. Ou seja, o impacto da distância reveste-se de uma dualidade com consequências distintas. Por um lado, as tripulações dos UAS fazem a Guerra a $10.000 \mathrm{~km}$ de distância, não se expondo aos rigores de combate. Por outro, estão apenas a 30 cm de distância do monitor que revela, em alta definição, os horrores que ocorrem em combate, fazendo aumentar o desejo de uso da força em situações de perigo iminente para as forças amigas. 
Assim, numa perspetiva moral, verificámos que esta modalidade traduz a dupla implicação do aumento da distância e da remoção do risco do duelo humano, continuando a tradição histórica de aumentar o afastamento físico entre os combatentes, mas acompanhando-o com uma desconexão psicológica. A tecnologia fomenta um determinado fenómeno de esterilidade emocional, substituindo a realidade por imagens virtuais, afastando os combatentes das consequências imediatas das suas ações, mas submetendo-os a um stress acrescido, com influência numa maior propensão para o uso da força.

Ao removermos o ser humano da luta direta poderemos estar a transformar a natureza da Guerra num dispendioso jogo de vídeo, tornando a atividade hostil numa mera transação económica. Por outro lado, a Guerra Aérea Remota veio demonstrar uma cruel realidade em que a morte em combate está limitada a um dos competidores, transformando a conflitualidade num estilo unilateral de Guerra Virtual. Esta alteração na demografia da Guerra, com a inclusão de uma nova geração "Playstation" com atributos militares completamente distintos dos combatentes tradicionais, obriga a reequacionar o ethos militar sob pena de se diluírem os padrões morais e éticos das instituições militares.

\section{BIBLIOGRAFIA}

AFI 14-104. 2012. Intelligence: oversight of intelligence activities. Washington DC: USAF. Alston, Phillip. 2010. Study on targeted killings. New York: United Nations.

Associated Press. 2008. Remote-control warriors suffer war stress. NBCNews.com, http: // www.msnbc.msn.com/id/26078087/\# (accessed March 8, 2013).

Bandura, Albert. 2004. The role of selective moral disengagement in terrorism and counterterrorism. In Understanding terrorism: Psychosocial roots, consequences and interventions, ed. Mogahaddam, F et al., 121-150. Washington DC: American Psychological Association.

Brulliard, Karin. 2010. Drone operators blamed in airstrike that killed Afghan civilians in February. The Washington Post, http: //www.washingtonpost.com/wp-dyn/content/article/2010/05/29/AR2010052901390.html (accessed March 8, 2013).

Bushey, Dean. 2011. The UAV Experience in Theatres. http: //www.iiss.org/about-us/offices/ washington/iiss-us-events/iiss-us-conference-the-future-of-unmanned-air-power/ (accessed March 8, 2013).

Chapelle, Wayne, Kent McDonald, and Raymond King. 2010. Psychological attributes critical to the performance of MQ-1 Predator and MQ-9 Reaper US Air Force Sensor Operators. Brooks City-Base: Air Force Research Laboratory.

Chapelle, Wayne, Amber Salinas, and Kent McDonald. 2011. Psychological Health Screening 
of Remotely Piloted Aircraft (RPA) Operators and Supporting Units. s.l.: NATO Research and Technology Organisation.

Clausewitz, Carl von. 1989. On War. Princeton: Princeton University Press.

Cole, Chris. 2012. US military investigation damns drone operators. Drone Wars UK, http: //dronewarsuk.wordpress.com/2012/03/28/us-military-investigation-damns-drone-operators/ (accessed March 8, 2013).

Dudziak, Mary. 2009. On drones and the war power. Legal History Blog, http: //legalhistoryblog.blogspot.com/2009/09/on-drones-and-war-power.html (accessed March 8, 2013).

Dunlap, Charles. 1999. Technology and the 21st Century Battlefield. Carlisle: Strategic Studies Institute.

Engelhardt, Tom. 2012. How drone war became the American way of life. Al Jazeera, http: //www.aljazeera.com/indepth/opinion/2012/02/201222791327288883.html (accessed March 8, 2013).

FAA. 2012. FAA Aerospace Forecast: Fiscal Years 2012-2032. Washington DC: Federal Aviation Administration.

Gavaghan, Julian. 2012. Is there a drone in your neighbourhood? Daily Mail, http: //www. dailymail.co.uk/news/article-2134376/Is-drone-neighbourhood-Rise-killer-spy-planes-exposed-FAA-forced-reveal-63-launch-sites-U-S.html (accessed March 8, 2013).

Gregory, Derek. 2011. Lines of Descent. Open Democracy, http://www.opendemocracy.net/ derek-gregory/lines-of-descent (accessed March 8, 2013).

Grossman, Dave, and Loren Christensen. 2008. On Combat: The Psychology and Physiology of Deadly Conflict in War and in Peace. Milstadt: Warrior Science Publications.

Grossman, Dave. 1996. On Killing: The Psychological Cost of Learning to Kill in War and Society. New York: Little Brown.

Jaffe, Greg. 2010. Combat Generation: Drone operators climb on winds of change in the Air Force. The Washington Post, http: //www.washingtonpost.com/wp-dyn/content/article/2010/02/27/AR2010022703754.html (accessed March 8, 2013).

Luttwak, Edward. 1995. Towards Post-Heroic Warfare. Foreign Affairs, Vol. 74, no. 3: 109-122.

Luttwak, Edward. 2000. Post-Heroic Warfare and its Implications. In Proceedings of International Symposium on Security Affairs - War and Peace in the 21st Century: Reflections upon the Century of War, ed. National Institute for Defense Studies. Tokyo: NIDS.

Luttwak, Edward. 2007. Dead End: Counterinsurgency Warfare as Military Malpractice. Harper's Magazine (February 2007), http: //harpers.org/archive/2007/02/0081384 (accessed March 8, 2013).

Martin, Matt, and Charles Sasser. 2010. Predator: The Remote-Control Air War over Iraq and Afghanistan - A Pilot's Story. Minneapolis: Zenith Press

Nagl, John. 2011. Kill/Capture. Frontline (PBS), http: //www.pbs.org/wgbh/pages/frontline/ afghanistan-pakistan/kill-capture/transcript/ (accessed March 8, 2013). 
Paumgarten, Nick. 2012. The World of Surveillance: Here's Looking at You. The New Yorker (May 14): 46-59.

Rasmussen, Robert. 2007. The wrong target: the problem of mistargeting resulting in fratricide and civilian casualties. Norfolk: Joint Forces Staff College.

Regan, Geoffrey. 1995. Blue on Blue: a history of friendly fire. New York: Avon Books.

Robinson, Jennifer. 2011. 'Bugsplat': The ugly US drone war in Pakistan. Al Jazeera, http: //www.aljazeera.com/indepth/opinion/2011/11/201111278839153400.html (accessed March 8, 2013).

Royakkers, L, and Van Est. 2010. The cubicle warrior: the marionette of digitalized warfare. Ethics and Information Technology, Vol. 12, no. 3: 289-296.

Saletan, William. 2008. Ghosts in the Machine: Do remote-control war pilots get combat stress? Slate, http: //www.slate.com/id/2197238 (accessed March 8, 2013).

Sifton, John. 2012. A Brief History of Drones. The Nation, http: //www.thenation.com/ article/166124/brief-history-drones (accessed March 8, 2013).

Singer, Peter. 2009a. Wired for War. New York: Penguin Press.

Singer, Peter. 2009b. Military Robots and the Laws of War. The New Atlantis, 23: 25-45.

Singer, Peter. 2010a. Meet the Sims...and Shoot Them. Foreign Policy, http: //www.brookings.edu/articles/2010/0222_video_game_warfare_singer.aspx (accessed March 8, 2013).

Singer, Peter. 2010b. The Soldiers Call It War Porn. Spiegel Online Interview, http: //www. spiegel.de/international/world/0,1518,682852,00.html (accessed March 8, 2013).

Sullins, John. 2009. Roboethics and Telerobotic Weapons Systems. IEEE International Conference on Robotics and Automation. Kobe: IEEE.

Trsek, Robert. 2008. "Hitting below the belt": moral and legal barriers to the pursuit of riskfree conflict. Montgomery: School of Advanced Air and Space Studies.

Tvaryanas, Anthony, William Platte, Caleb Swigart, Jayson Colebank, and Nita Miller. 2008. A Resurvey of Shift Work-Related Fatigue in MQ-1 Predator Unmanned Aircraft System Crewmembers. Monterey: Naval Post-Graduate School.

US Congress Report. 2012. FAA Reauthorization: Excerpts on Unmanned Aircraft Systems. Washington DC: US Congress.

Wilson, G. 2011. The Psychology of Killer Drones: action against our foes; reaction affecting us. Fabius Maximus, http: //fabiusmaximus.wordpress.com/2011/09/28/29263/ (accessed March 8, 2013).

Zoroya, Gregg. 2011. U.S. drone operators show signs of exhaustion. USA Today, http: //www. usatoday.com/news/military/story/2011-12-18/study-drone-operators-exhaustion/52053016/1 (accessed March 8, 2013).

Zucchino, David, and David Cloud. 2011. U.S. deaths in drone strike due to miscommunication, report says. Los Angeles Times, http: //www.latimes.com/news/nationworld/world/ la-fg-pentagon-drone-20111014,0,4026563.story (accessed March 8, 2013). 
Sistemas Aéreos Não Tripulados, ou como designados na gíria, de drones.

2 Para uma análise detalhada ver Bandura (2004).

3 Relembre-se a expressão contemporânea "Axis of Evil" introduzida pelo Presidente George Bush num discurso do Estado da União em 2002.

4 Em referência a jogos de computador em que o objetivo é esmagar baratas. Este termo atribui uma conotação depreciativa, sub-humana, ao caracterizar os alvos como vermes, fazendo reavivar a terminologia introduzida por Hitler ao referenciar os judeus como parasitas e vermes (Robinson, 2011).

5 O CENTCOM divulgou a 22 de março de 2012 a versão completa do relatório da investigação (Cole, 2012).

6 Comparativamente com não combatentes, os operadores de Reaper e Predator apresentavam uma maior incidência de exaustão emocional, enquanto os níveis de cinismo (atitude profissional negativa) e a eficácia profissional eram mais baixos (Ibidem: 19-1).

7 Tradução do termo original "militainment" que reflete a tendência atual de esbatimento entre o entretenimento e a Guerra. 